\title{
Investigation of the Effect of Different Current Loads on the Arc-Erosion Performance of Electrical Contacts
}

\author{
S. BIYIK ${ }^{a, *}$ AND M. AYDIN ${ }^{b}$ \\ ${ }^{a}$ Karadeniz Technical University, Department of Metallurgical and Materials Engineering, 61080 Trabzon, Turkey \\ ${ }^{b}$ Karadeniz Technical University, Department of Mechanical Engineering, 61080 Trabzon, Turkey \\ In this study, arc-erosion experiments using contactors were performed under inductive loads for up to \\ 40000 switching operations to investigate the effect of different current loads on the arc-erosion performance of \\ electrical contacts. Determination of the mass loss was performed after every 5000 operations. The arc-eroded sur- \\ faces were examined using scanning electron microscopy. The chemical composition near the arc was determined by \\ energy dispersive X-ray spectroscopy. The results show that the contact surfaces are greatly affected by arc-erosion, \\ resulting in mass loss due to material migration and/or evaporation. In addition, the arc-affected zones become \\ bigger with the increase in the number of switching operations, especially at $20 \mathrm{~A}$. However, electrical cleaning \\ improves the contact performance by reducing the contact resistance due to breakdown of the non-conducting oxide \\ films formed between 20000 and 25000 switching operations at $20 \mathrm{~A}$. The stationary contacts experience major \\ erosion, whereas the movable contacts suffered less contact erosion under each current load.
}

DOI: 10.12693/APhysPolA.129.656

PACS/topics: 81.70.-q, 07.50.--e, 84.32.Dd

\section{Introduction}

Electrical contacts control single or multiple electric circuits by turning them on or off and are critical for the successful operation of all products that use electricity. A contact material must have reliable characteristics such as high electrical and thermal conductivity, high resistance to arc-erosion and welding, low vapor pressure and high resistance to the deteriorating effects of oxide, sulfide, and other compounds that cause insulation on contact surfaces [1]. Otherwise, arc-originated material evaporation leads to high amount of contact erosion [2]. Hence, some parameters such as safety and reliability levels, contact life, and cost should be taken into consideration when selecting a suitable contact material for different applications. The proper choice of contact materials for specific applications depends on the type of supply ( $\mathrm{AC} / \mathrm{DC})$, current level, type of loads (inductive, capacitive, resistive, or motor), contact forces, and number and frequency of make/break cycles [3]. For example, the deterioration of contact surfaces occurs with the increase in the number of switching operations resulting from the current; consequently, the shortening of useful life is inevitable. Failures of electrical contacts have resulted in severe consequences, e.g., energy collapse in a megalopolis, failure in telephone systems, and even airplane crashes [1]. Therefore, examination of the make/break operations of electrical contacts, and control of the arc formation play a significant role in selecting a new material or improving existing materials for electrical contacts.

*corresponding author; e-mail: serkanbiyik@ktu.edu.tr
In this context, some performance tests are required. One of the most important performance tests of electrical contact materials is the arc-erosion test. Many studies have been conducted using arc-erosion testing equipment on the manufacture and evaluation of various contact materials, including some composites, to investigate electrical performance [4-11]. The main purpose of these studies is to predict the lifespan of electrical contacts, which can assist in eliminating or minimizing contact failures. Thus, the contact lifetime can be increased by improving the arc-erosion performance or mitigating the negative effects of arcs. However, the effect of current loads on the arc deterioration has not yet been investigated in detail. Furthermore, in conventional test rigs, the current load cannot be raised to high levels. Therefore, the primary purpose of the present study is to investigate the effect of current load on the performance of electrical contacts via arc-erosion experiments.

\section{Materials and methods}

The arc-erosion test rig that can operate over a wide range of current loads is shown in Fig. 1. The main components of the test rig are the contactor, electronic flasher, up/down counter, energy analyzer, operatingtime indicator, rotary switch, current activating and switching buttons, and emergency stop button (Fig. 1a). The test rig also includes circuit breakers, a cooling system, and transformers, which supply inductive loads to achieve real-life operating conditions (Fig. 1b). The equipment can operate at medium-duty current loads of up to $30 \mathrm{~A}$ via the control buttons in the device. In the present work, the current load value of the system was gradually adjusted to the specified levels, namely, 10 and $20 \mathrm{~A}$. The electronic flasher controls the switching parameters such as the make/break counts (cycle) 
and delay times of the electrical contacts with high precision. In addition, switching numbers can be readily adjusted to the desired counts and monitored on the LCD screen of the up/down counter. The test rig also has an energy analyzer capable of monitoring the current load.

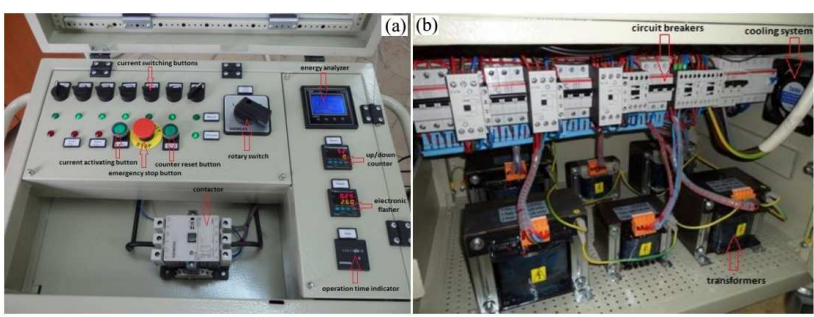

Fig. 1. Photographs of the arc-erosion test rig: (a) control panel, and (b) part of the test rig showing the transformers, cooling system, and circuit breakers.

Arc-erosion experiments were performed under the following testing conditions: an operating voltage of $220 \mathrm{~V}$, a frequency of $50 \mathrm{~Hz}$, and switching currents of 10 and $20 \mathrm{~A}$. Because current load values lower than $10 \mathrm{~A}$ are insufficient to establish a minimum voltage and current that can generate a stable electrical arc and display no appreciable arc-related electrical wear, they are not considered in the tests. The switching frequency and delay time were selected as 1000 operations per hour and $2.6 \mathrm{~s}$, respectively. Arc-erosion experiments were carried out on three-pole contactors at a switching power of $37 \mathrm{~kW}$ and a contact current of $75 \mathrm{~A}$ for up to 40000 operations. The mass-loss values of the electrical contacts were determined at every 5000 operations using a semi-microanalytical balance (KERN ABT 220-5DM) with a precision of $10^{-5} \mathrm{~g}$. Subsequently, arc-eroded surfaces were analyzed by scanning electron microscopy [(SEM) Zeiss Evo LS 10]. The chemical composition of the degraded contact surfaces was determined by energy dispersive $\mathrm{X}$ ray spectroscopy (EDS) analysis. Using this process, the effect of the current load on the arc-erosion performance of the contacts was investigated, and the arc-generated deterioration under increasing number of switching operations was evaluated.

\section{Results and discussion}

The erosion losses in electrical contacts are listed in Table I. The values in this table were determined using the measurement results at every 5000 switching operations for both stationary and movable contacts under 10 and 20 A currents. Figure 2 shows the curves of the variation in the mass loss with the number of switching operations for both contacts. The mass loss in both contacts increased with the increase in the number of switching operations. However, at certain values corresponding to 20000-25000 operations, no considerable mass loss has occurred. These critical points occurred at not more than approximately 5000 operations. Thereafter, both contacts generally lost mass again. In addition, the mass loss in the stationary contacts was higher than that in the movable contacts at each current load, especially at $20 \mathrm{~A}$.

TABLE I

Mass-loss values of both stationary and movable contacts tested using 10 and 20 A current loads.

\begin{tabular}{|c|c|c|c|c|c|c|}
\hline \multirow[t]{2}{*}{$\begin{array}{c}\text { Switching } \\
\text { number }\end{array}$} & \multicolumn{2}{|c|}{$\begin{array}{c}\text { Mass loss of } \\
\text { movable contacts } \\
{[\mathrm{mg}]} \\
\end{array}$} & \multicolumn{2}{|c|}{$\begin{array}{c}\text { Mass loss of } \\
\text { stationary contacts } \\
{[\mathrm{mg}]}\end{array}$} & \multicolumn{2}{|c|}{$\begin{array}{c}\text { Overall } \\
\text { mass loss } \\
{[\mathrm{mg}]} \\
\end{array}$} \\
\hline & $10 \mathrm{~A}$ & $20 \mathrm{~A}$ & $10 \mathrm{~A}$ & $20 \mathrm{~A}$ & $10 \mathrm{~A}$ & $20 \mathrm{~A}$ \\
\hline 5000 & 0.59 & 1.14 & 1.21 & 1.62 & 1.80 & 2.76 \\
\hline 10000 & 0.96 & 1.30 & 1.82 & 2.55 & 2.78 & 3.85 \\
\hline 15000 & 1.51 & 1.72 & 2.16 & 3.39 & 3.67 & 5.11 \\
\hline 20000 & 2.00 & 2.30 & 2.86 & 4.05 & 4.86 & 6.35 \\
\hline 25000 & 2.22 & 2.47 & 3.35 & 4.21 & 5.57 & 6.68 \\
\hline 30000 & 2.81 & 2.93 & 3.84 & 4.95 & 6.65 & 7.88 \\
\hline 35000 & 3.03 & 3.14 & 4.52 & 5.80 & 7.55 & 8.94 \\
\hline 40000 & 3.23 & 3.49 & 4.74 & 5.93 & 7.97 & 9.42 \\
\hline
\end{tabular}

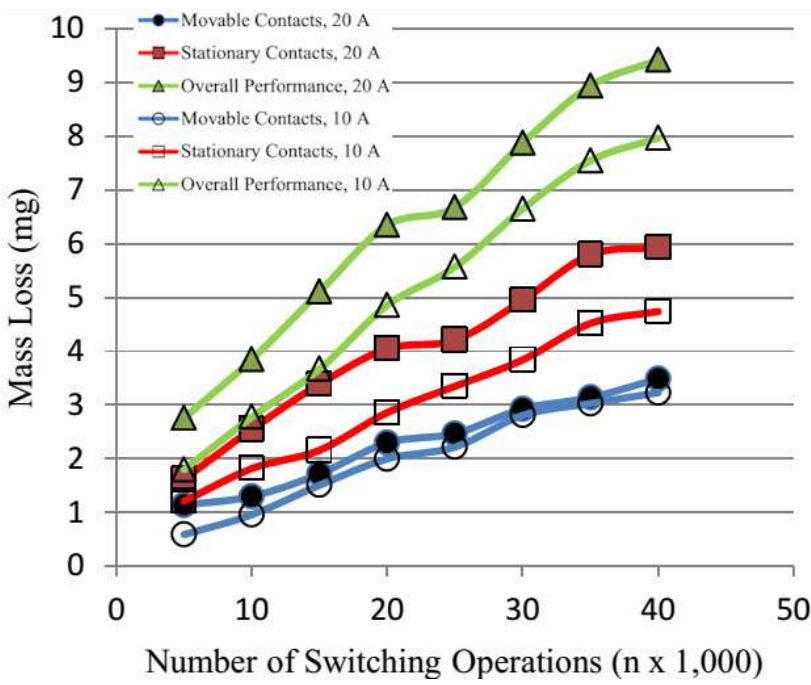

Fig. 2. Graph of the mass loss versus switching number for both contacts tested at 10 and $20 \mathrm{~A}$.

The curves that characterize the degradation mechanisms of the electrical contacts caused by arc-erosion can be divided into three stages. In this regard, the earlier stages of the tests, namely, those that range up to 20000 operations are called the "initial stage". The range that corresponds to switching operations between 20000 and 25000 is referred to as the "intermediate stage". The number of operations in the region from 25000 to 40000 is called the "final stage".

The mass loss during the initial stage constitutes a fairly high portion of the total mass loss, especially in the stationary contacts. This result could be attributed to the surface roughness characteristics of the contacts. Depending on the surface roughness of the materials, the actual surface area of the intersection is much smaller than the area that can be observed at a macroscopic 
scale. In fact, the area of the intersection of the contacts consists of small hills, as viewed from the microscopic scale, and the actual contact area between the contacts is the sum of these points. Therefore, the current is constricted through these small effective areas during the initial stage, i.e., the contact resistance is relatively higher during this period [3]. Thus, excessive mass loss is observed at this stage. Figure 3a shows that small cavities are formed on the surface of the stationary contacts, whereas Fig. 3b shows that mound-shaped buildup occurred on the surface of the movable contacts. The surface deterioration in the contacts is mainly caused by the formation of a small molten bridge of metal just before the separation of the contacts, and material is transferred into the movable contact from the stationary contact. Over time, the deposit on the surface of the movable contact gradually increases and assumes a more domed shape (Fig. 3d). On the other hand, a shallow crater is formed on the opposite contact (Fig. 3c).
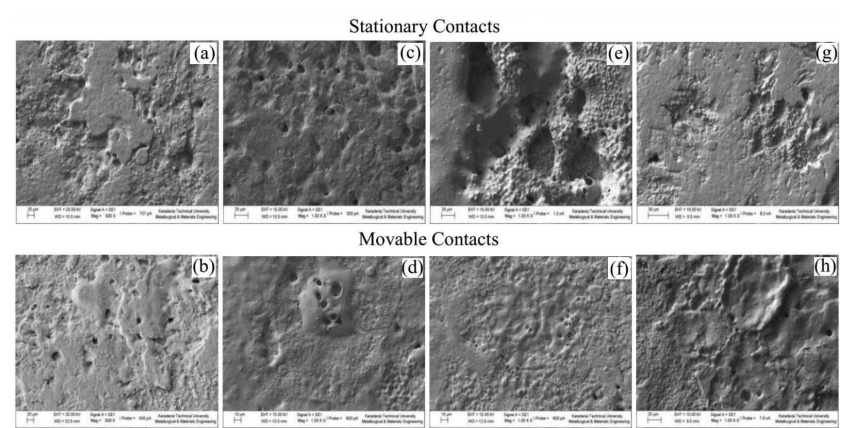

Fig. 3. SEM micrographs showing the surfaces of both contacts tested at $10 \mathrm{~A}$ for different switching numbers: (a, b) 5000; (c, d) 20000; (e, f) 25000; (g, h) 40000.

The mass loss remained nearly stable, especially in the movable contacts, for switching operation in range between 20000 and 25000, as shown in Fig. 2. The "intermediate stage" can be considered as a critical stage for the movable contacts because their mass loss remained nearly stable (Fig. 3f). The improved arc-erosion performance of the movable contacts in this critical stage is attributed to the electrothermal cleaning effect. However, the 10 A current was insufficient in establishing an electrothermal cleaning effect on the stationary contacts (Fig. 3e). This effect was partially achieved at the final stages of the tested contacts at 10 A (Fig. 3g). Therefore, the non-conductive oxide layers on the contact surface were not electrically destroyed (Fig. 3h). Consequently, the contact resistance remained at higher values than those under reliable conditions.

The variation in the mass loss with the increase in the number of switching operations for the $20 \mathrm{~A}$ current load was generally similar to that for the $10 \mathrm{~A}$ load, as shown in Fig. 4. In particular, the movable contacts remained almost in the same regime. However, during the initial period of the arc-erosion tests (up to 20000 cycles), the mass loss with the 20 A load was higher than that

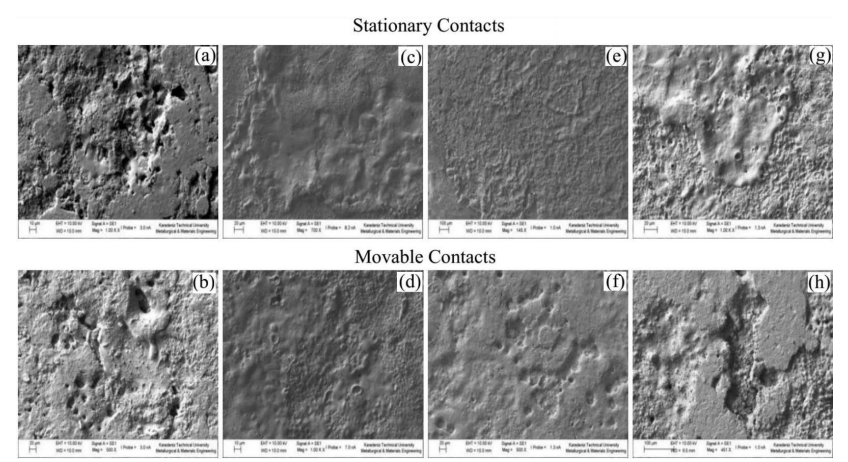

Fig. 4. SEM micrographs showing the surfaces of both contacts tested at $20 \mathrm{~A}$ for different switching numbers: (a, b) 5000; (c, d) 20000; (e, f) 25000; (g, h) 40000.

with the 10 A current intensity (Table I). This extreme mass loss during the initial stage of the arc-erosion experiments was mainly due to the surface roughness phenomenon described earlier. In addition, the arc deterioration was much more intense in the contacts tested using $20 \mathrm{~A}$, which resulted from the increased circuitcurrent load. Therefore, the arc-deteriorated zones were more pronounced than those that occurred in the first test $(10 \mathrm{~A})$, as shown in Fig. 4a and b. Furthermore, the mass loss in the stationary contacts was higher than that in the movable contacts during this period, especially up to 10000 switching operations. However, at certain numbers of switching operations corresponding to 20000 and 25000 cycles, very limited mass loss occurred in both contacts. The SEM micrographs obtained from the relatively smooth surfaces of both contacts with the 20 A current intensity confirm this result, as shown in Fig. 4c-f. The intersection points of the contact area increased, and the arc distribution widened from small points to large areas. This situation also reduced the mechanical forces per unit area on the contact surfaces, which helps in avoiding or minimizing the formation of microcracks that can induce detrimental effects on sustaining the mechanical strength. Besides, the effect of electrical cleaning due to sufficient current load could be observed for switching operations between 20000 and 25000 on both contacts tested using $20 \mathrm{~A}$. This effect is advantageous in terms of obtaining minimal relative mass loss between the contacts via lowering the contact resistance. After the critical point, the deteriorating effects of the arc reemerged in the form of material outgrowth in the stationary contacts and craters in the movable contacts, as shown in Fig. $4 \mathrm{~g}$ and h, respectively.

Tables II and III list the chemical compositions of the electrical contacts in the arc-affected zones for 25000 and 40000 switching operations, respectively. The primary elements of these contacts are silver, copper, tin, and iron, whereas the minor constituents are bismuth, cadmium, graphite, aluminum, and silicon. By comparing Table II and Table III, it can be seen that the amount of silver content has decreased from $57.11 \%$ to $45.38 \%$ with the 
TABLE II

Chemical composition of the contacts in the arc-affected zones after 25000 operations.

\begin{tabular}{c|c|c|c|c|c|c|c|c|c|c}
\hline \hline & \multicolumn{7}{|c}{ Chemical composition [wt\%] } \\
\hline $\begin{array}{c}\text { Type of } \\
\text { contact }\end{array}$ & $\mathrm{Ag}$ & $\mathrm{Cu}$ & $\mathrm{Sn}$ & $\mathrm{Fe}$ & $\mathrm{Bi}$ & $\mathrm{Cd}$ & $\mathrm{C}$ & $\mathrm{Al}$ & $\mathrm{Si}$ & $\mathrm{O}$ \\
\hline $\begin{array}{c}\text { Stationary } \\
\text { contact }\end{array}$ & 58.12 & 5.13 & 4.84 & 2.93 & 2.32 & 1.78 & 1.10 & 0.29 & 0.23 & 23.29 \\
$\begin{array}{c}\text { Movable } \\
\text { contact }\end{array}$ & 57.11 & 15.15 & 4.41 & 0.69 & 1.53 & 1.69 & 1.26 & 0.03 & 0.05 & 18.07
\end{tabular}

TABLE III

Chemical composition of the contacts in the arc-affected zones after 40000 operations.

\begin{tabular}{c|c|c|c|c|c|c|c|c|c|c}
\hline \hline & \multicolumn{7}{|c}{ Chemical composition [wt\%] } \\
\hline $\begin{array}{c}\text { Type of } \\
\text { contact }\end{array}$ & $\mathrm{Ag}$ & $\mathrm{Cu}$ & $\mathrm{Sn}$ & $\mathrm{Fe}$ & $\mathrm{Bi}$ & $\mathrm{Cd}$ & $\mathrm{C}$ & $\mathrm{Al}$ & $\mathrm{Si}$ & $\mathrm{O}$ \\
\hline $\begin{array}{c}\text { Stationary } \\
\text { contact } \\
\text { Movable } \\
\text { contact }\end{array}$ & 57.02 & 8.85 & 9.64 & 5.54 & 2.89 & 1.20 & 2.58 & 0.25 & 0.14 & 11.89 \\
& 45.38 & 26.91 & 7.72 & 2.08 & 2.15 & 0.95 & 2.40 & 0.06 & 0.09 & 12.26
\end{tabular}

increasing switching number. This decrease originates from the melting and evaporation of silver, which has a low melting point. On the other hand, copper, which has a higher melting point than silver, was deposited in the vicinity of the regions with insufficient silver.

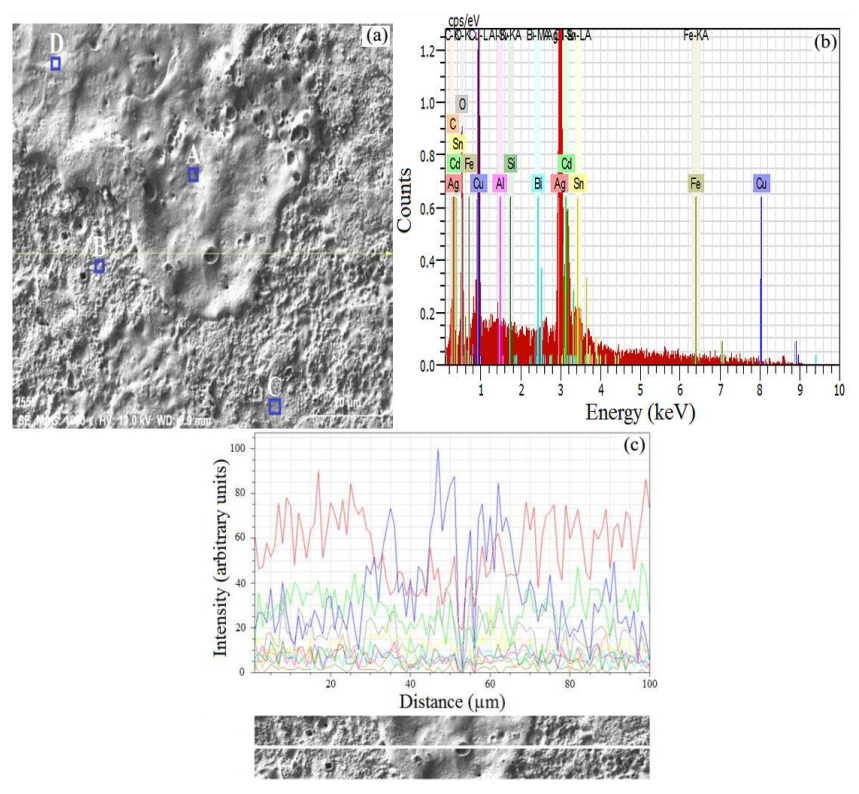

Fig. 5. Line-scan and point-analysis reports of the stationary contact tested at $20 \mathrm{~A}$ after 40000 operations: (a) SEM image; and (b) EDS result of the region in (a); and (c) corresponding line scan analysis.

The combined results of the line-scan and point analyses of the stationary contact, which was tested at $20 \mathrm{~A}$ after 40000 switching operations, are shown in Fig. 5a-c.
The line-scan analysis report shows that the major constituents of the molten region of the alloy in the liquid phase were copper $(30.96 \%)$ and silver $(28.53 \%)$. Other elements in this region were iron $(15.92 \%)$, tin $(13.57 \%)$, and some minor additives that consisted of bismuth, cadmium, graphite, aluminum, and silicon (Fig. 5b). It can be seen from Fig. $5 \mathrm{c}$ that the regions with higher copper content, associated primarily with the high intensity blue-colored copper peaks, are easily affected by the arc via melting. However, the strength against melting and arc-erosion is increased with the increase in the cadmium content, as shown with the increasing frequency of the green-colored cadmium peaks outside the molten region.

TABLE IV

Element distribution at different points of the arc-affected zones of the contacts after 40000 cycles.

\begin{tabular}{c|c|c|c|c|c|c|c|c|c|c}
\hline \hline & \multicolumn{10}{|c}{ Chemical composition [wt\%] } \\
\hline Zone & $\mathrm{Ag}$ & $\mathrm{Cu}$ & $\mathrm{Sn}$ & $\mathrm{Fe}$ & $\mathrm{Bi}$ & $\mathrm{Cd}$ & $\mathrm{C}$ & $\mathrm{Al}$ & $\mathrm{Si}$ & $\mathrm{O}$ \\
\hline $\mathrm{A}$ & 28.53 & 30.96 & 13.57 & 15.92 & 2.44 & 0.56 & 0.75 & 0.83 & 0.65 & 5.79 \\
$\mathrm{~B}$ & 49.04 & 11.72 & 5.60 & 18.24 & 2.69 & 2.89 & 1.40 & 0.78 & 1.05 & 6.60 \\
$\mathrm{C}$ & 49.30 & 19.85 & 6.03 & 11.18 & 1.93 & 1.02 & 1.33 & 0.32 & 0.31 & 8.73 \\
$\mathrm{D}$ & 41.40 & 31.43 & 5.04 & 11.21 & 2.66 & 0.40 & 1.15 & 0.55 & 0.27 & 5.91
\end{tabular}

In addition to the line-scan analysis, four different points were selected on the SEM micrograph, which represented the chemical composition near the arc-affected melting zone. The results are listed in Table IV. According to the data shown in Table IV, zone A had a minimum silver content, whereas the tin content was the highest among all zones. Even though zones B and C had approximately the same silver content, zone B had a higher iron content than zone $\mathrm{C}$, while zone $\mathrm{C}$ had a higher copper content than zone B. Due to the effect of the changes in the element distribution, zones $\mathrm{B}$ and $\mathrm{C}$ displayed different appearance because a locally melted region was more evident at zone $\mathrm{C}$. In addition, the cadmium content at zone $\mathrm{B}(2.89 \%)$ was higher than that at zone $\mathrm{C}(1.02 \%)$. This result is consistent with the data obtained from the arc-erosion experiments conducted by other researchers [6]. Similar to zone A, zone $\mathrm{D}$ was severely damaged by the deteriorating effects of the arc due to the very small amount of cadmium content $(0.40 \%)$ in this region.

In addition to the line and point scan analyses, EDS mapping was also performed to observe the distribution of the elements near the arc-affected zones (Fig. 6a-c). The bright areas in Fig. 6a show the distribution of silver (colored red), and some minor elements such as tin and bismuth in the EDS map. The same figure also shows that microcracks were formed in the areas close to the zones damaged by the arc. As a result of the EDS mapping, we have determined that the damaged regions consisted of low cadmium content but high amount of copper and oxygen elements (Fig. $6 \mathrm{~b}$ and c). In addition, copper oxide compounds have likely formed in the aforementioned areas. The oxidizing films formed on contact surfaces can initially spread over the contours of the 


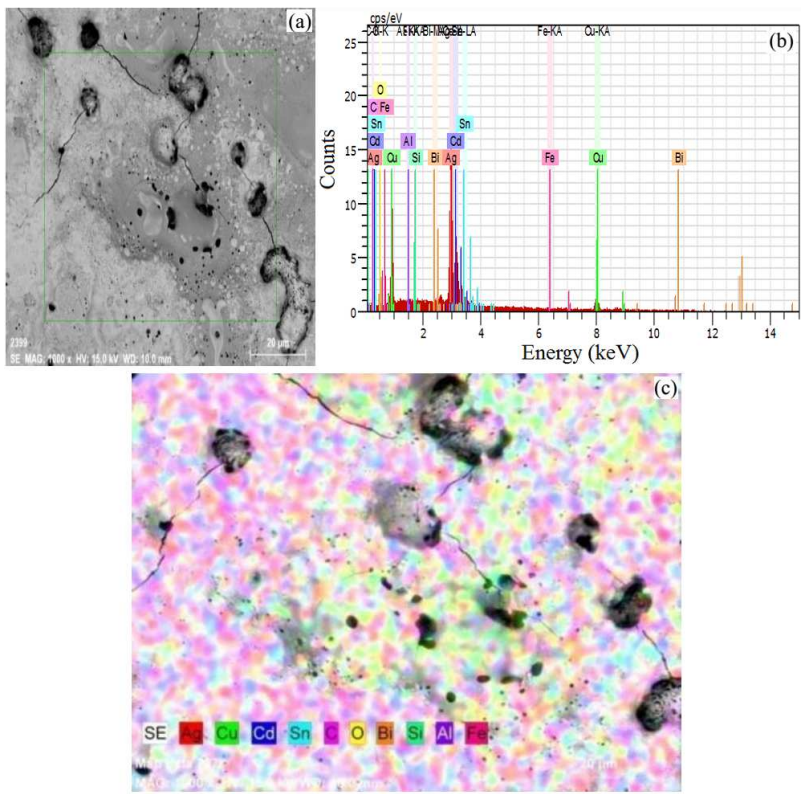

Fig. 6. EDS mapping report showing the element distribution on the surface of the movable contact after 20000 operations at 10 A: (a) SEM image; (b) EDS result of the region in (a); and (c) corresponding elemental EDS map.

contacts and then propagate to the inner sides. In such a case, the oxidizing films on the surface may cause a disturbance in the electrical conductivity and increase the contact resistance. Consequently, control of the arc becomes more difficult, and the surface-deterioration rate increases. In addition, ambient conditions also affect the oxidation behavior of the contacts. Therefore, the chemical composition, especially in the vicinity of the microcracks has a strong effect on the arc-erosion performance of the contact material.

\section{Conclusions}

The mass losses in both stationary and movable contacts increased with the increase in the number of switching operations at current intensities of 10 and $20 \mathrm{~A}$. Compared with the movable contacts, the stationary contacts exhibited higher mass loss at up to 40000 switching operations. The effect of electrical cleaning was apparent for operations between 20000 and 25000 for the contacts tested at $20 \mathrm{~A}$. This phenomenon is beneficial in terms of the contact performance because it reduces the contact resistance back to the lower levels via breakdown of the non-conductive oxide films formed on the contact surfaces. However, the effect disappeared during the final stages of the arc-erosion experiments for the contacts tested at $10 \mathrm{~A}$, namely, at 35000 and 40000 switching operations. The chemical composition of the nearby arc has affected the surface deterioration in both movable and stationary contacts as the EDS line-scan and point analyses show. We have observed that the mass losses of the movable contacts were independent of the intensity of the current load, whereas the stationary contacts exhibited increasing mass losses with the increase in the current load.

\section{Acknowledgments}

This work was supported by the Scientific Research Fund of Karadeniz Technical University (KTUBAP, Project No: 1073).

\section{References}

[1] M. Braunovic, N.K. Myshkin, V.V. Konchits, Electrical Contacts: Fundamentals, Applications and Technology, CRC Press, Florida 2006.

[2] V. Gurevich, Electric Relays: Principles and Applications, CRC Press, Florida 2005.

[3] P.G. Slade, Electrical Contacts: Principles and Applications, CRC Press, Florida 2014.

[4] S. Biyik, F. Arslan, M. Aydin, J. Electron. Mater. 44, 457 (2015).

[5] Q. Shi, J. Yang, W.X. Peng, J.Z. Dong, Y.Q. Chu, H. Tang, C.S. Li, RSC Adv. 5, 100472 (2015).

[6] F. Pons, M. Cherkaoui, I. Ilali, S. Dominiak, J. Electron. Mater. 39, 456 (2010).

[7] S. Biyik, M. Aydin, Proc. IEEE 15th Int. Conf. on Thermal, Mechanical and Multi-Physics Simulation and Experiments in Microelectronics and Microsystems (EuroSimE), Ghent 2014, p. 1.

[8] D. Wojcik-Grzybek, K. Frydman, P. Borkowski, Arch. Metall. Mater. 58, 1059 (2013).

[9] J. Wang, D. Li, Y. Wang, J. Alloy. Compd. 582, 1 (2014).

[10] S. Biyik, M. Aydin, Acta Phys. Pol. A 127, 1255 (2015).

[11] S. Biyik, M. Aydin, Proc. Int. Conf. on High Performance and Optimum Design of Structures and Materials, (HPSM/OPTI), Ostend (2014), p. 189. 